\title{
Prevalence of Enterobius vermicularis among preschool children in 2003 and 2013 in Xinxiang city, Henan province, Central China
}

\author{
Shuai Wang ${ }^{1, a}$, Zhijun Yao ${ }^{1, a}$, Yichen $\mathrm{Hou}^{2, a}$, Dong Wang ${ }^{1}$, Haizhu Zhang ${ }^{1}$, Jingbo Ma ${ }^{1}$, \\ Luwen Zhang ${ }^{1}$, and Shiguo Liu ${ }^{1, *}$ \\ 1 Department of Human Parasitology, School of Basic Medical Sciences, Xinxiang Medical University, Xinxiang, Henan 453003, \\ PR China \\ 2 Class-2012 Grade of Department of Anesthesiology, Medical College of Nanchang University, Nanchang, Jiangxi 330006, PR China
}

Received 8 April 2016, Accepted 12 July 2016, Published online 26 July 2016

\begin{abstract}
The present study was performed to assess the prevalence of Enterobius vermicularis infection among preschool children in Xinxiang city, Henan province, China and the changes in the egg positive rate for E. vermicularis over a 10 year period. A total of 510 preschool children in 17 kindergartens were examined using the cellophanetape perianal swab method in 2003, while 1734 preschool children in 10 kindergartens were examined in 2013 using the same method. The overall egg positive rate for E. vermicularis was $12.75 \%$ (65 out of 510 ) in 2003 and $5.13 \%$ (89 out of 1734) in 2013; the former was significantly higher than the latter $(p<0.05)$. In both 2003 and 2013, the egg positive rate for 5 to 6 -year-old children was significantly higher than that of 2 to 4 -year-old children $(p<0.05)$. However, positive rates were not significantly dependent on gender or area. Among selected personal hygiene factors, no hand washing before eating, sucking fingers or toys, and scratching around the anus were all associated with enterobiasis. The present study confirmed that the prevalence of E. vermicularis infection among preschool children decreased significantly over the 10 year period in Xinxiang city, but infection was still prevalent. Improving sanitation and personal hygiene practices, especially hand washing, could help prevent the transmission of E. vermicularis.
\end{abstract}

Key words: Enterobius vermicularis, Enterobiasis, Prevalence, Preschool children, Central China.

\begin{abstract}
Résumé - Prévalence d'Enterobius vermicularis chez les enfants d'âge préscolaire en 2003 et 2013 dans la ville de Xinxiang, province du Henan, Chine centrale. La présente étude a été réalisée pour évaluer la prévalence de l'infection par Enterobius vermicularis chez les enfants d'âge préscolaire dans la ville de Xinxiang, province du Henan, en Chine et les changements dans le taux de positivité pour oeufs d'E. vermicularis sur une période de dix ans. Un total de 510 enfants d'âge préscolaire dans 17 jardins d'enfants ont été examinés à l'aide de la méthode de prélèvement périanal par bande de cellophane en 2003, tandis que 1734 enfants d'âge préscolaire dans 10 jardins d'enfant sont été examinés en 2013 en utilisant la même méthode. Le taux global de positivité pour œufs d'E. vermicularis était de $12.75 \%$ (65 sur 510) en 2003 et $5.13 \%$ (89 sur 1734) en 2013, le premier étant significativement plus élevé que le second $(p<0.05)$. En 2003 et 2013, le taux de positivité d'œufs des enfants de 5 à 6 ans était significativement plus élevé que pour les enfants de 2 à 4 ans $(p<0.05)$. Cependant, les taux n'étaient pas significativement dépendants du sexe et du quartier. Parmi les facteurs d'hygiène personnelle sélectionnés, l'absence de lavage des mains avant de manger, sucer les doigts ou des jouets, se gratter autour de l'anus ont été tous associés à l'oxyurose. La présente étude a confirmé que la prévalence de l'infection à E. vermicularis des enfants d'âge préscolaire a diminué de façon significative au cours des dix dernières années à Xinxiang, mais l'infection est encore répandue. Améliorer l'assainissement et la pratique de l'hygiène personnelle, en particulier le lavage des mains, pourrait aider à prévenir la transmission d'E. vermicularis.
\end{abstract}

\footnotetext{
${ }^{a}$ Authors with the same contribution to this paper.

*Corresponding author: 1sg1963@163.com
}

This is an Open Access article distributed under the terms of the Creative Commons Attribution License (http://creativecommons.org/licenses/by/4.0), which permits unrestricted use, distribution, and reproduction in any medium, provided the original work is properly cited. 


\section{Introduction}

Enterobiasis is a nematode infection caused by the pinworm, Enterobius vermicularis [11]. The principal mode of transmission of $E$. vermicularis is direct contact between infected and uninfected persons [16]. For this reason, it is usually endemic in overcrowded conditions, such as kindergartens and primary schools, due to easy transmission from infected to uninfected children [12].

Enterobiasis is asymptomatic in most adults who have low worm burdens. However, in children, particularly those with high worm burdens, neurological symptoms including nervousness, restlessness, irritability, and distraction may occur, and these may influence child growth [13, 14, 18].

E. vermicularis infection is prevalent throughout the world, including in developed countries [4, 8, 13, 14, 18], and it is estimated that $4-28 \%$ of children are infected globally [1]. E. vermicularis infection is also widespread among preschool children in the People's Republic of China (China). According to the 2011 national parasitic survey, the average prevalence of E. vermicularis infection in children reached $17.8 \%$ in China, with the highest prevalence rates in Hainan (51.1\%), Guangxi (26.7\%), and Guangdong (26.7\%) [2]. In 2011, the overall prevalence of $E$. vermicularis infection reached $54.86 \%$ in Gaozhou city, Guangdong province, southern China [12].

Currently, little information is available regarding the prevalence and possible risk factors of enterobiasis among kindergarten children in the central provinces of China. Therefore, in this study, we evaluated the prevalence of E. vermicularis among kindergarten children in Xinxiang city, Henan province, a province of central China, and performed a comparative analysis of the state of E. vermicularis prevalence in children in the years 2003 and 2013.

\section{Materials and methods}

\section{Ethics statement}

The study was reviewed and approved by the Ethics Review Committee of the Xinxiang Medical University (Reference Nos. 2003008 and 2013012). All examinations were carried out with permission from the preschool teachers and the children's parents.

\section{Subject recruitment}

The study was conducted in Xinxiang city, Henan province, central China. A total of 510 preschool children (282 boys and 228 girls) in 17 kindergartens were recruited for the survey in 2003, while 1734 preschool children (918 boys and 816 girls) in 10 kindergartens were recruited in 2013. Seven of the selected 17 kindergartens in 2003 merged with the 10 remaining kindergartens before the year 2013. We therefore recruited preschool children from the 10 remaining kindergartens in 2013. After 10 years of development, the scale of enrollment of the 10 kindergartens expanded, along with the increase in the number of classrooms and teachers in these schools. The average number of teachers in each class increased from
Table 1. Egg positive rate of Enterobius vermicularis in children in studies in 2003 and 2013.

\begin{tabular}{ccccc}
\hline Year & No. examined & No. positive & Prevalence $(\%)$ & $p$-value \\
\hline 2003 & 510 & 65 & 12.75 & $<0.001$ \\
2013 & 1734 & 89 & 5.13 & \\
\hline
\end{tabular}

two to three. Conversely, the average number of students in each class decreased from 35 to 30 . The infrastructures of kindergartens, such as toilets and playground equipment, are much cleaner and more spacious than 10 years ago.

\section{Questionnaire survey}

The questionnaire included questions on basic information regarding the children and their personal hygiene habits (see Table 2). Personal data included age, gender, and residential district. The children's personal hygiene habits section aimed to gather information on certain behaviors, including hand washing before eating, sucking fingers (including fingernail biting) or toys, and scratching around the anus.

\section{Detection of $E$. vermicularis infection}

Egg detection for E. vermicularis was performed using the cellophane-tape perianal swab method, as previously described [6], which was performed by parents between 07:30 and 09:30 in the morning, according to the instructions provided by the study researchers, and all samples were collected by the teachers at every kindergarten. Collected samples were then transported to the Department of Human Parasitology, Xinxiang Medical University, and examined under light microscope. The same detection procedure was performed on three consecutive days. If eggs were found, children were considered positive for E. vermicularis infection.

\section{Statistical analysis}

Statistical analysis was performed using SPSS 20 software for Windows (SPSS Inc, Chicago, Illinois, USA). Statistical analyses of $E$. vermicularis prevalence for different variables were performed by $\chi^{2}$-test. The differences were considered statistically significant if $p<0.05$.

\section{Results}

In 2003, a total of $65(12.75 \%)$ of the 510 samples were positive for E. vermicularis eggs. After 10 years, the egg positive rate significantly decreased to $5.13 \%(89 / 1734)$ in 2013 (Table 1).

Table 2 shows the personal hygiene practices and other factors that may potentially be associated with the egg positive rates of E. vermicularis. No significant differences in egg positive rates according to gender were observed in 2003 or 2013. The egg positive rate in rural areas was only slightly 
Table 2. Results of univariate analysis of risk factors and Enterobius vermicularis infection in the study participants.

\begin{tabular}{|c|c|c|c|c|c|c|c|c|}
\hline \multirow[t]{2}{*}{ Variable } & \multicolumn{4}{|c|}{2003} & \multicolumn{4}{|c|}{2013} \\
\hline & No. examined & No. positive & Prevalence $(\%)$ & $\overline{p \text {-value }}$ & No. examined & No. positive & Prevalence $(\%)$ & $p$-value \\
\hline \multicolumn{9}{|l|}{ Gender } \\
\hline Male & 282 & 39 & 13.83 & \multirow[t]{2}{*}{0.414} & 918 & 53 & 5.77 & \multirow[t]{2}{*}{0.200} \\
\hline Female & 228 & 26 & 11.40 & & 816 & 36 & 4.41 & \\
\hline \multicolumn{9}{|c|}{ Age (years) } \\
\hline $2-4$ & 367 & 40 & 10.90 & \multirow[t]{2}{*}{0.045} & 894 & 26 & 2.91 & \multirow[t]{2}{*}{$<0.001$} \\
\hline $5-6$ & 143 & 25 & 17.48 & & 840 & 63 & 7.50 & \\
\hline \multicolumn{9}{|l|}{ Area } \\
\hline Urban & 253 & 30 & 11.86 & \multirow[t]{2}{*}{0.551} & 994 & 49 & 4.93 & \multirow[t]{2}{*}{0.65} \\
\hline Rural & 257 & 35 & 13.62 & & 740 & 40 & 5.41 & \\
\hline \multicolumn{9}{|c|}{ Hand washing before eating } \\
\hline Yes & 238 & 22 & 9.24 & \multirow[t]{2}{*}{0.027} & 1156 & 41 & 3.55 & \multirow[t]{2}{*}{$<0.001$} \\
\hline No & 272 & 43 & 15.81 & & 578 & 48 & 8.30 & \\
\hline \multicolumn{9}{|c|}{ Sucking fingers or toys } \\
\hline Yes & 381 & 53 & 13.91 & \multirow[t]{2}{*}{0.175} & 981 & 63 & 6.42 & \multirow[t]{2}{*}{0.00} \\
\hline No & 129 & 12 & 9.30 & & 753 & 26 & 3.45 & \\
\hline \multicolumn{9}{|c|}{ Scratching around the anus } \\
\hline Yes & 287 & 41 & 14.29 & \multirow[t]{2}{*}{0.237} & 611 & 52 & 8.51 & \multirow[t]{2}{*}{$<0.001$} \\
\hline No & 223 & 24 & 10.76 & & 1123 & 37 & 3.29 & \\
\hline
\end{tabular}

higher than that in urban areas in both 2003 and 2013. However, this difference was not significant $(p>0.05)$.

In 2003 , the egg positive rate among 5 to 6 -year-old children $(17.48 \%, 25 / 143)$ was significantly higher than that among 2 to 4-year-old children $(10.90 \%, 40 / 367, p<0.05)$. Similarly, the egg positive rate among 5 to 6 -year-old children was also significantly higher than that among 2 to 4 -year-old children $(7.50 \%$ vs. $2.91 \%, p<0.001)$ in 2013 (Table 2).

Among selected personal hygiene factors, hand washing before eating, sucking fingers or toys, and scratching around the anus, were all associated with enterobiasis. Children who wash their hands before eating had lower egg positive rates for $E$. vermicularis than those who did not $(p<0.05)$. Children with the habit of sucking fingers or toys were more commonly infected by $E$. vermicularis than those who did not have this habit; this result was significant in $2013(p<0.01)$ but not in $2003(p>0.05)$. Similar results were found in the children with the habit of scratching around the anus or not.

\section{Discussion}

Although enterobiasis is generally considered to be a nuisance rather than a serious disease, the level of morbidity is significant, particularly in children.

This study found that the overall prevalence of E. vermicularis infection in preschool children was $12.75 \%$ in 2003 and $5.13 \%$ in 2013 in Xinxiang. With the implementation of the National major parasitic diseases prevention and control project (2006-2015) and the National soil source nematode disease prevention and control project (2006-2015) (National Health and Family Planning Commission [NHFPC] of the People's Republic of China), awareness levels of enterobiasis among children's carers, such as teachers and parents, as well as health behavior training rates of children, have clearly increased. In addition, almost full coverage of non-hazardous sanitary toilets in the countryside has been achieved. Moreover, the average number of students in each class of the kindergarten decreased from 35 to 30 . The infrastructures of kindergartens such as toilets and playground equipment are much cleaner and more spacious than 10 years ago. These changes might explain why the prevalence of $E$. vermicularis infection has decreased to a low level in Xinxiang.

In the present study, the egg positive rate for E. vermicularis among 5 to 6 -year-old children was also significantly higher than that among 2 to 4-year-old children in both 2003 and 2013. Five to 6-year-old children might have more frequent contact in kindergartens than children 2-4 years of age. The egg positive rate for E. vermicularis was also found to significantly increase with age, as previously reported [6, 7]. With regard to gender, no significant statistical difference was observed between boys and girls, which was consistent with other reports $[12,15,18]$.

According to previous reports regarding risk factors for $E$. vermicularis infection, inadequate personal hygiene increased the risk of enterobiasis among primary school children [9, 11, 17]. E. vermicularis can be transmitted from person to person by contaminated hands, especially in crowded conditions [3]. Children who did not mention that they should wash their hands with soap before eating had higher concentrations of $E$. vermicularis eggs on their hands $(p<0.05)$ than those who did [3]. In the present study, children who wash their hands before eating had lower egg positive rates for E. vermicularis than those who did not. These studies highlight the need to teach children to get into the recommended habit of washing hands at school and at home, under the supervision of teachers and parents, respectively, to prevent transmission of E. vermicularis.

Furthermore, in our study, children with the habit of sucking fingers or toys showed higher rates of $E$. vermicularis infection than those who did not have this habit. This was 
consistent with previous reports [5, 9, 10]. For younger children, guardians should pay close attention to cleaning toys and prohibit children from sucking fingers or toys.

It is therefore necessary not only to carry out mass screening and regular whole group treatments for children, with correct medication methods, but also to develop pinworm eradication programs, such as health education programs on enterobiasis for parents, in order to control E. vermicularis infection in China.

In conclusion, the prevalence of E. vermicularis infection among preschool children decreased significantly over a period of 10 years in Xinxiang city, but E. vermicularis infection was still prevalent. Therefore, specific control measures are required to interrupt the transmission cycle of $E$. vermicularis. Larger scale studies are required to establish the extent of the infection in other parts of China.

\section{Conflict of interest}

The authors declare no conflict of interest in relation with this paper.

Acknowledgements. This study was supported by the Doctoral Scientific Research Activation Foundation of Xinxiang Medical University (No. XYBSKYZZ201504) and the Key Scientific and Technological Project of Xinxiang City (No. ZG15014).

\section{References}

1. Bethony J, Brooker S, Albonico M, Geiger SM, Loukas A, Diemert D, Hotez PJ. 2006. Soil-transmitted helminth infections: ascariasis, trichuriasis, and hookworm. Lancet, 367(9521), 1521-1532.

2. Chen YD, Wang JJ, Zhu HH, Zhu TJ, Zang W, Qian MB, Li HM, Zhou CH, Wang GF, Xu LQ. 2013. Enterobius vermicularis infection status among children in 9 provinces/ autonomous regions/municipalities of China. Chinese Journal of Parasitology and Parasitic Diseases, 31(4), 251-255 (in Chinese).

3. Cranston I, Potgieter N, Mathebula S, Ensink JH. 2015. Transmission of Enterobius vermicularis eggs through hands of school children in rural South Africa. Acta Tropica, 150, 94-96.

4. Dutto M, Montu D, Raineri G. 2012. Enterobiasis in pediatric subjects in north-western Italy: a study of home remedies. Annali di Igiene, 24(1), 81-84.

5. Herrstrom P, Fristrom A, Karlsson A, Hogstedt B. 1997. Enterobius vermicularis and finger sucking in young Swedish children. Scandinavian Journal of Primary Health Care, 15(3), 146-148.

6. Hong SH, Jeong YI, Lee JH, Cho SH, Lee WJ, Lee SE. 2012. Prevalence of Enterobius vermicularis among preschool children in Muan-gun, Jeollanam-do Korea. Korean Journal of Parasitology, 50(3), 259-262.
7. Hong SH, Lee SE, Jeong YI, Lee WJ, Cho SH. 2011. Comparison of egg positive rates of Enterobius vermicularis among preschool children in three Korean localities. Korean Journal of Parasitology, 49(4), 441-443.

8. Kim DH, Cho MK, Park MK, Kang SA, Kim BY, Park SK, Yu HS. 2013. Environmental factors related to enterobiasis in a southeast region of Korea. Korean Journal of Parasitology, 51(1), 139-142.

9. Kim DH, Son HM, Kim JY, Cho MK, Park MK, Kang SY, Kim BY, Yu HS. 2010. Parents' knowledge about enterobiasis might be one of the most important risk factors for enterobiasis in children. Korean Journal of Parasitology, 48(2), 121-126.

10. Kim DH, Son HM, Lee SH, Park MK, Kang SA, Park SK, Choi JH, Park JH, Yu HS. 2015. Negligible egg positive rate of Enterobius vermicularis and no detection of head lice among orphanage children in Busan and Ulsan, Korea (2014). Korean Journal of Parasitology, 53(4), 497-499.

11. Kim DH, Yu HS. 2014. Effect of a one-off educational session about enterobiasis on knowledge, preventative practices, and infection rates among schoolchildren in South Korea. PLoS One, 9(11), e112149.

12. Li HM, Zhou CH, Li ZS, Deng ZH, Ruan CW, Zhang QM, Zhu TJ, Xu LQ, Chen YD. 2015. Risk factors for Enterobius vermicularis infection in children in Gaozhou, Guangdong, China. Infectious Diseases of Poverty, 4, 28.

13. Neghina R, Dumitrascu V, Neghina AM, Vlad DC, Petrica L, Vermesan D, Tirnea L, Mazilu O, Olariu TR. 2013. Epidemiology of ascariasis, enterobiasis and giardiasis in a Romanian western county (Timis), 1993-2006. Acta Tropica, 125(1), 98-101.

14. Otu-Bassey IB, Useh MF, Alaribe AA. 2011. The posttreatment effects of enterobiasis on the occurrence of enuresis among children in Calabar, Nigeria. Asian Pacific Journal of Tropical Medicine, 4(4), 315-319.

15. Park JH, Han ET, Kim WH, Shin EH, Guk SM, Kim JL, Chai JY. 2005. A survey of Enterobius vermicularis infection among children on western and southern coastal islands of the Republic of Korea. Korean Journal of Parasitology, 43(4), 129-134.

16. Patsantara GG, Piperaki ET, Tzoumaka-Bakoula C, Kanariou MG. 2015. Immune responses in children infected with the pinworm Enterobius vermicularis in central Greece. Journal of Helminthology, 1(3), 1-5.

17. Peixoto A, Goncalves R, Silva M, Gaspar R, Silva R, Portugal R, Macedo G. 2015. Eosinophilic ileocolitis due to Enterobius vermicularis infection: a rare cause of anemia. International Journal of Colorectal Disease, 31(3), 1.

18. Salim N, Schindler T, Abdul U, Rothen J, Genton B, Lweno O, Mohammed AS, Masimba J, Kwaba D, Abdulla S, Tanner M, Daubenberger C, Knopp S. 2014. Enterobiasis and strongyloidiasis and associated co-infections and morbidity markers in infants, preschool- and school-aged children from rural coastal Tanzania: a cross-sectional study. BMC Infectious Diseases, 14, 644. 
Cite this article as: Wang S, Yao Z, Hou Y, Wang D, Zhang H, Ma J, Zhang L \& Liu S: Prevalence of Enterobius vermicularis among preschool children in 2003 and 2013 in Xinxiang city, Henan province, Central China. Parasite, 2016, 23, 30.

\section{- PARASTE}

An international open-access, peer-reviewed, online journal publishing high quality papers on all aspects of human and animal parasitology

Reviews, articles and short notes may be submitted. Fields include, but are not limited to: general, medical and veterinary parasitology; morphology, including ultrastructure; parasite systematics, including entomology, acarology, helminthology and protistology, and molecular analyses; molecular biology and biochemistry; immunology of parasitic diseases; host-parasite relationships; ecology and life history of parasites; epidemiology; therapeutics; new diagnostic tools.

All papers in Parasite are published in English. Manuscripts should have a broad interest and must not have been published or submitted elsewhere. No limit is imposed on the length of manuscripts.

Parasite (open-access) continues Parasite (print and online editions, 1994-2012) and Annales de Parasitologie Humaine et Comparée (1923-1993) and is the official journal of the Société Française de Parasitologie. 